\title{
Thermal ablation in cancer (Review)
}

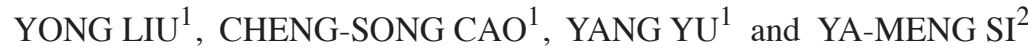 \\ Departments of ${ }^{1}$ Internal Medicine-Oncology, and ${ }^{2}$ Oral and Maxillofacial Surgery, \\ Xuzhou Central Hospital, Xuzhou, Jiangsu 221009, P.R. China
}

Received April 1, 2016; Accepted July 27, 2016

DOI: $10.3892 / \mathrm{ol} .2016 .4997$

\begin{abstract}
Radiofrequency ablation (RFA) and cryoablation are alternative forms of therapy used widely in various pathological states, including treatment of carcinogenesis. The reason is that ablation techniques have ability of modulating the immune system. Furthermore, recent studies have applied this form of therapy on tumor microenvironment and in the systematic circulation. Moreover, RFA and cryoablation result in an inflammatory immune response along with tissue disruption. Evidence has demonstrated that these procedures affect carcinogenesis by causing a significant local inflammatory response leading to an immunogenic gene signature. The present review enlightens the current view of these techniques in cancer.
\end{abstract}

\section{Contents}

1. Introduction

2. Cryoablation and cancer

3. Surgical diathermy

4. RFA and its associated effects

5. Cryosurgery in cancer

6. Mechanism behind cryosurgery/RFA

7. Conclusion

\section{Introduction}

Interventional procedures involving exposure to extreme temperatures to cause local tissue damage are termed as thermal ablation (1). The two most commonly used procedures that comprise thermal ablation, are radiofrequency ablation (RFA) and cryoablation. The two procedures involve the introduction of a metal probe using ultrasound or computed

Correspondence to: Dr Ya-Meng Si, Department of Oral and Maxillofacial Surgery, Xuzhou Central Hospital, 199 Jiefang Road, Xuzhou, Jiangsu 221009, P.R. China

E-mail: 403627437@qq.com

Key words: ablation, tumor, cancer, radiofrequency ablation, cryoablation tomography (CT) guidance as a visual aid. Small tumors are usually destroyed by exposing them to two different temperature extremes, high burning temperature via RFA and freezing tissue cold temperature via cryoablation.

In terms of local treatment strategies, cryoablation is an attractive treatment modality as it is safe and effective in the treatment of kidney, liver, bone, lung, adrenal and soft tissue masses $(2,3)$. Furthermore, it is palliative in nature as the freezing procedure causes a local analgesic effect. Cost effectiveness is another positive aspect of cryoablation. Additionally, cryosurgery is another ablation method showing progress in prostate and breast cancer subjects and has thus become a widely applied technique in research for both immunologists and oncologists $(2,3)$.

\section{Cryoablation and cancer}

Cryoablation has been reported to induce microvascular thrombosis, membrane disruption, solution effects, ice crystallization and organelle disruption in cancer cells (4). These differentially induced processes affect cells variably and eventually result in apoptosis or even necrotic cell death (5). Reiter et al observed that cryotherapy was more effective in exerting an antitumor effect by virtue of cell necrosis as compared to ultraviolet (UV)-induced apoptosis in bone marrow-derived murine macrophage (6). Sauter et al evidenced the specificity of cryotherapy by inducing necrosis on immature dendritic cells (DCs) as they have ability to induce apoptosis and necrosis (7).

Previous studies have focused on the nature of cryotherapy-induced immune effects, i.e., immunosuppressive or immune-stimulatory. The 'danger' theory suggested the immune system is capable of recognizing any cell injury as a threat, thereby inducing responses. This is termed immune-stimulatory (8). Similarly, cryotherapy-induced necrosis is immune-stimulatory in nature as it leads to the denaturing of proteins or cell wall breakdown. Immune stimulation during cryotherapy is visible in the form of high mobility group box 1 (HMGB1) inflammatory factor, uric acid, and heat shock proteins (HSPs), including hsp70 and hsp90 (9). On the other hand, apoptosis is immune suppressive in nature and unable to release HMGB1 (10). Scheffer et al studied protective attributes of the two processes and observed that apoptotic cells induced significant protection and prolonged survival, while necrotic cell vaccine provided little protection (11). Conversely, Kotera et al found pulsing DCs with apoptotic cells produced 
by UVB exposure showed immune-stimulatory effects (12). Gamrekelashvili et al used ganciclovir to induce tumor cell apoptosis and a vascular targeting drug, ZD6126, to process necrotic tumor cells, thereby observing both immune-stimulatory as well as immune-suppressive effects (13). Feng et al also observed both these effects in leukemic cells (14). Therefore, the induction of necrotic and apoptotic cells is important in the generation of an immune-reactive or immunosuppressive response and cryosurgery is an important contributor to the management of carcinogenesis.

\section{Surgical diathermy}

Kolicher for the first time evidenced the efficacy of surgical diathermy during cancer in 1910 (15). The key player in this form of therapy was observed to be the reticuloendothelial system. In surgical diathermy, RFA is often utilized for therapeutic exposures. McGahan et al demonstrated the local effects of RFA via ultrasound including necrosis, hemorrhage and congestion in swine models (16). RFA was reported to cause statistically significant infiltration of $\mathrm{T}$ cells in a hepatoma model in rabbits (17). Additionally, in the combination approach, RFA together with CTLA4 was reported to be more effective against tumor and proved successful in the enhancement of survival (18).

\section{RFA and its associated effects}

RFA resulted in T-cell response together with the infiltration of DCs within tumors in a murine urothelial carcinoma model (19). In humans, RFA has been reported to be effective in metastatic liver tumors during hepatocellular carcinoma (HCC) (20). In an additional study, RFA promoted the release of interferon (IFN)- $\gamma$ following the procedure (21). In another study, in 20 patients with localized HCC unfit for liver transplantation or surgical resection, RFA proved beneficial by promoting the frequency of circulation of IFN- $\gamma$-positive cells (22). Zerbini et al showed that RFA is also capable of inducing maturation of antigen-presenting cells (APCs) capable of producing specific T cells for HCC (23).

\section{Cryosurgery in cancer}

The approach of cryosurgery has also been reported to have an immune-stimulatory and immunosuppressive nature (24). Myers et al used mouse models for fibrosarcoma and mammary tumors to observe the effectiveness of cryosurgery (25). Using a rat model, Blackwood and Cooper found that animals who received cryoablation for myosarcoma and carcinosarcoma cell line-derived tumors were protected against intraperitoneal implantation (26). Neel et al also compared surgical approach and cryoablation in mice with virally-induced mammary adenocarcinoma or chemically-induced sarcoma. The results of that study showed that cryoablation was more efficient in improving survival time after tumor rechallenge (27).

\section{Mechanism behind cryosurgery/RFA}

The in vivo melanoma mouse model was utilized to determine mechanisms underlying cryosurgery, RFA and tumor vaccination. RFA and cryosurgery appeared to produce an in situ depot of tumor antigen and debris. These approaches have been observed to cause an increase in immature DCs within tumor draining lymph nodes that ultimately cause tumor invasion. Furthermore, as discussed earlier, the combination therapy was more beneficial and effective through the addition of anti-CTLA4 to any thermal ablation approach, whether. cryosurgery or RFA (18). It has also been suggested in the literature that these approaches result in an increased ratio of effector CD8 T cells compared to T-regulatory cells, thereby resulting in a systemic specific immunity.

\section{Conclusion}

Based on the above literature it can be concluded that thermal ablation procedures affect carcinogenesis by causing a significant local inflammatory response leading to an immunogenic gene signature. However, additional studies are required to clinically confirm the outcomes and to make it a gold standard therapy for the management of cancer patients.

\section{Acknowledgements}

The present study is supported by the Six Major Talent Peak Project no. 2014-WSW-065 and the Wu Jieping Foundation for Clinical Research of Medical Science Foundation no. 320.6750 .15255 .

\section{References}

1. Voigt JD and Barnett G: The value of using a brain laser interstitial thermal therapy (LITT) system in patients presenting with high grade gliomas where maximal safe resection may not be feasible. Cost Eff Resour Alloc 14: 6, 2016.

2. Alblin RJ, Soanes WA and Gonder MJ: Prospects for cryo-immunotherapy in cases of metastasizing carcinoma of the prostate. Cryobiology 8: 271-279, 1971.

3. Suzuki Y: Cryosurgical treatment of advanced breast cancer and cryoimmunological responses. Skin Cancer 10: 19-26, 1995.

4. Sabel MS: Cryo-immunology: a review of the literature and proposed mechanisms for stimulatory versus suppressive immune responses. Cryobiology 58: 1-11, 2009.

5. Gallucci S, Lolkema M and Matzinger P: Natural adjuvants: endogenous activators of dendritic cells. Nat Med 5: 1249-1255, 1999.

6. Reiter I, Krammer B and Schwamberger G: Cutting edge: differential effect of apoptotic versus necrotic tumor cells on macrophage antitumor activities. J Immunol 163: 1730-1732, 1999.

7. Sauter B, Albert ML, Francisco L, Larsson M, Somersan S and Bhardwaj N: Consequences of cell death: exposure to necrotic tumor cells, but not primary tissue cells or apoptotic cells, induces the maturation of immunostimulatory dendritic cells. J Exp Med 191: 423-434, 2000.

8. Matzinger P: Tolerance, danger, and the extended family. Annu Rev Immunol 12: 991-1045, 1994.

9. Shi Y, Evans JE and Rock KL: Molecular identification of a danger signal that alerts the immune system to dying cells. Nature 425: 516-521, 2003.

10. Scaffidi P, Misteli T and Bianchi ME: Release of chromatin protein HMGB1 by necrotic cells triggers inflammation. Nature 418: 191-195, 2002.

11. Scheffer SR Sr, Nave H, Korangy F, Schlote K, Pabst R, Jaffee EM Manns MP and Greten TF: Apoptotic, but not necrotic, tumor cell vaccines induce a potent immune response in vivo. Int $\mathrm{J}$ Cancer 103: 205-211, 2003.

12. Kotera Y, Shimizu K and Mulé JJ: Comparative analysis of necrotic and apoptotic tumor cells as a source of antigen(s) in dendritic cell-based immunization. Cancer Res 61: 8105-8109, 2001. 
13. Gamrekelashvili J, Krüger C, von Wasielewski R, Hoffmann M, Huster KM, Busch DH, Manns MP, Korangy F and Greten TF: Necrotic tumor cell death in vivo impairs tumor-specific immune responses. J Immunol 178: 1573-1580, 2007.

14. Feng H, Zeng Y, Graner MW and Katsanis E: Stressed apoptotic tumor cells stimulate dendritic cells and induce specific cytotoxic T cells. Blood 100: 4108-4115, 2002.

15. Kolischer G. Surgical diathermy in malignancy. Am J Surg 7: 249-250, 1929.

16. McGahan JP, Brock JM, Tesluk H, Gu WZ, Schneider P and Browning PD: Hepatic ablation with use of radio-frequency electrocautery in the animal model. J Vasc Interv Radiol 3: 291-297, 1992.

17. Wissniowski TT, Hänsler J, Neureiter D, Frieser M, Schaber S, Esslinger B, Voll R, Strobel D, Hahn EG and Schuppan D: Activation of tumor-specific $\mathrm{T}$ lymphocytes by radio-frequency ablation of the VX2 hepatoma in rabbits. Cancer Res 63 6496-6500, 2003.

18. den Brok MH, Sutmuller RP, van der Voort R, Bennink EJ, Figdor CG, Ruers TJ and Adema GJ: In situ tumor ablation creates an antigen source for the generation of antitumor immunity. Cancer Res 64: 4024-4029, 2004.

19. Dromi SA, Walsh MP, Herby S, Traughber B, Xie J, Sharma KV, Sekhar KP,Luk A, Liewehr DJ, Dreher MR, et al: Radiofrequency ablation induces antigen-presenting cell infiltration and amplification of weak tumor-induced immunity. Radiology 251: 58-66, 2009 .

20. Napoletano C, Taurino F, Biffoni M, De Majo A, Coscarella G Bellati F, Rahimi H, Pauselli S, Pellicciotta I, Burchell JM, et al: RFA strongly modulates the immune system and anti-tumor immune responses in metastatic liver patients. Int J Oncol 32: 481-490, 2008
21. Hansler J, Wissniowski TT, Schuppan D, Witte A, Bernatik T, Hahn EG and Strobel D: Activation and dramatically increased cytolytic activity of tumor specific $\mathrm{T}$ lymphocytes after radio-frequency ablation in patients with hepatocellular carcinoma and colorectal liver metastases. World J Gastroenterol 12: 3716-3721, 2006.

22. Zerbini A, Pilli M, Penna A, Pelosi G, Schianchi C, Molinari A, Schivazappa S, Zibera C, Fagnoni FF, Ferrari C, et al: Radiofrequency thermal ablation of hepatocellular carcinoma liver nodules can activate and enhance tumor-specific T-cell responses. Cancer Res 66: 1139-1146, 2006.

23. Zerbini A, Pilli M, Fagnoni F, Pelosi G, Pizzi MG, Schivazappa S, Laccabue D, Cavallo C, Schianchi C, Ferrari C, et al: Increased immunostimulatory activity conferred to antigen-presenting cells by exposure to antigen extract from hepatocellular carcinoma after radiofrequency thermal ablation. J Immunother 31: 271-282, 2008.

24. Sidana A, Chowdhury WH, Fuchs EJ and Rodriguez R: Cryoimmunotherapy in urologic oncology. Urology 75: 1009-1014, 2010.

25. Myers RS, Hammond WG and Ketcham AS: Tumor-specific transplantation immunity after cryosurgery. J Surg Oncol 1: 241-246, 1969

26. Blackwood CE and Cooper IS: Response of experimental tumor systems to cryosurgery. Cryobiology 9: 508-515, 1972.

27. Neel HB III, Ketcham AS and Hammond WG: Experimental evaluation of in situ oncocide for primary tumor therapy: comparison of tumor-specific immunity after complete excision, cryonecrosis and ligation. Laryngoscope 83: 376-387, 1973. 